\title{
APP Causes Hyperexcitability in Fragile X Mice
}

\author{
Cara J. Westmark ${ }^{1 *}$, Shih-Chieh Chuang ${ }^{2 \dagger}$, Seth A. Hays ${ }^{3 \dagger}$, Mikolaj J. Filon ${ }^{1}$, Brian C. Ray ${ }^{1}$, \\ Pamela R. Westmark ${ }^{4}$, Jay R. Gibson ${ }^{3}$, Kimberly M. Huber ${ }^{3}$ and Robert K. S. Wong ${ }^{2}$ \\ ${ }^{1}$ Department of Neurology, University of Wisconsin-Madison, Madison, Madison, WI, USA, ${ }^{2}$ Department of Physiology and \\ Pharmacology, State University of New York Downstate Medical Center, Brooklyn, NY, USA, ${ }^{3}$ Department of Neuroscience, \\ University of Texas Southwestern Medical Center, Dallas, TX, USA, ${ }^{4}$ Department of Medicine, University of \\ Wisconsin-Madison, Madison, Madison, WI, USA
}

OPEN ACCESS

Edited by:

Susan A. Masino,

Trinity College, USA

Reviewed by:

Barbara Bardoni,

CNRS UMR7275 Institut de

Pharmacologie Moléculaire et

Cellulaire, France

Niraj S. Desai,

University of Texas at Austin, USA

*Correspondence:

Cara J. Westmark westmark@facstaff.wisc.edu

${ }^{\dagger}$ These authors have contributed equally to this work.

Received: 26 September 2016 Accepted: 01 December 2016 Published: 15 December 2016

Citation:

Westmark CJ, Chuang S-C, Hays SA,

Filon MJ, Ray BC, Westmark PR, Gibson JR, Huber KM and Wong RKS (2016) APP Causes Hyperexcitability in Fragile X Mice.

Front. Mol. Neurosci. 9:147. doi: 10.3389/fnmol.2016.00147
Amyloid-beta protein precursor (APP) and metabolite levels are altered in fragile $X$ syndrome (FXS) patients and in the mouse model of the disorder, $F m r 1^{K O}$ mice. Normalization of APP levels in Fmr1 ${ }^{K O}$ mice (Fmr1 ${ }^{K O} / A P P H E T$ mice) rescues many disease phenotypes. Thus, APP is a potential biomarker as well as therapeutic target for FXS. Hyperexcitability is a key phenotype of FXS. Herein, we determine the effects of APP levels on hyperexcitability in $F m r 1^{\mathrm{KO}}$ brain slices. $F m r 1^{\mathrm{KO}} / \mathrm{APP} H E T$ slices exhibit complete rescue of UP states in a neocortical hyperexcitability model and reduced duration of ictal discharges in a CA3 hippocampal model. These data demonstrate that APP plays a pivotal role in maintaining an appropriate balance of excitation and inhibition (E/I) in neural circuits. A model is proposed whereby APP acts as a rheostat in a molecular circuit that modulates hyperexcitability through mGluR $_{5}$ and FMRP. Both over- and under-expression of APP in the context of the Fmr1 ${ }^{\mathrm{KO}}$ increases seizure propensity suggesting that an APP rheostat maintains appropriate E/I levels but is overloaded by mGluR $_{5}$-mediated excitation in the absence of FMRP. These findings are discussed in relation to novel treatment approaches to restore APP homeostasis in FXS.

Keywords: amyloid-beta, amyloid-beta precursor protein, fragile $\mathrm{X}$ mental retardation protein, fragile $\mathrm{X}$ syndrome, hyperexcitability

\section{INTRODUCTION}

Amyloid-beta protein precursor (APP) levels are dysregulated in numerous neurological disorders that are comorbid with a seizure phenotype including fragile X syndrome (FXS) (Westmark, 2013). FXS is a trinucleotide repeat disorder caused by a CGG repeat expansion at the $5^{\prime}$-end of the FMR1 gene. Hypermethylation of the repeat expansion results in transcriptional silencing of the FMR1 gene and loss of expression of fragile $\mathrm{X}$ mental retardation protein (FMRP) (Jin and Warren, 2000). FMRP is an RNA binding protein (RBP) that plays a pivotal role in synaptic function. It is one of numerous RBP that interact with amyloid precursor protein (App) mRNA to regulate post-transcriptional and/or translational events involved in the synthesis of APP (Westmark and Malter, 2012). Specifically, FMRP binds to a guanine-rich region in the coding region of App mRNA and regulates APP translation through a metabotropic glutamate receptor $5\left(\mathrm{mGluR}_{5}\right)$-dependent pathway (Westmark and Malter, 2007). We hypothesize that altered expression of APP in FXS contributes to disease severity. In support of this hypothesis, genetic knockout of one App allele in $F m r 1^{K O}$ mice $\left(F m r 1^{K O} / A P P^{H E T}\right.$ mice) reduces APP expression in the $F m r 1^{K O}$ to wild type (WT) levels and rescues audiogenic-induced seizures (AGS), the percentage of mature spines, open field 
and marble burying behavioral phenotypes, and mGluR-LTD (Westmark et al., 2011). APP and metabolite levels are altered in Fmr1 ${ }^{K O}$ mice and FXS patients (Sokol et al., 2006; Westmark et al., 2011; Erickson et al., 2014; Pasciuto et al., 2015; Ray et al., 2016). Thus, APP is a potential therapeutic target as well as bloodbased biomarker for FXS (Berry-Kravis et al., 2013; Westmark et al., 2016), and it is of interest to determine the effect(s) of APP levels on additional disease phenotypes. Herein, we ascertain the effects of App knockdown on hyperexcitability in the $F m r 1^{K O}$ mouse.

\section{GENETIC REDUCTION OF APP RESCUES HYPEREXCITABILITY IN Fmr1 ${ }^{K O}$ MICE}

The psychiatric phenotype of FXS includes hyperexcitability traits such as tactile defensiveness, attention deficits, hyperactivity, and hyperarousal to sensory stimulation (Tranfaglia, 2011). There is high comorbidity of epilepsy in FXS with electroencephalogram (EEG) patterns most often consisting of a centrotemporal spike pattern resembling Benign Focal Epilepsy of Childhood (BFEC) (Berry-Kravis, 2002). Hyperexcitability can be modeled in the $F m r 1^{K O}$ mice both in vivo and in vitro (brain slices). In vivo, the $F m r 1^{K O}$ mice are susceptible to AGS (Chen and Toth, 2001). In the AGS model, mice are exposed to $110 \mathrm{~dB}$ siren, which elicits out-of-control (wild) running and jumping followed by convulsive seizures and often death. There is substantial evidence that dysregulated APP expression alters seizure propensity. AGS are exacerbated by overexpression of APP in the $F m r 1^{K O}$ mouse (FRAXAD mice) and partially rescued by reduced expression of APP in Fmr1 ${ }^{K O} / A P P^{H E T}$ mice (Westmark et al., 2010, 2011). Alzheimer's disease (Tg2576) and Down syndrome (Ts65Dn) mice, which overexpress human and mouse APP respectively, are highly susceptible to AGS (Westmark et al., 2010). Numerous mouse models that express altered APP or metabolite levels exhibit elevated rates of spontaneous or provoked seizures (Moechars et al., 1996; Steinbach et al., 1998; Del Vecchio et al., 2004; Lalonde et al., 2005; Palop et al., 2007; Kobayashi et al., 2008; Westmark et al., 2008; Minkeviciene et al., 2009; Ziyatdinova et al., 2011; Sanchez et al., 2012) while suppression of transgenic APP in Alzheimer's disease mice during postnatal development delays the onset of EEG abnormalities (Born et al., 2014).

In brain slices, hyperexcitability can be measured by recording UP states and epileptiform discharges. UP states are short periods of local network activity that generate a steady-state level of depolarization and synchronous firing among groups of neighboring neurons (Gibson et al., 2008). $F m r 1^{K O}$ mice exhibit an increased duration of the UP state, consistent with network hyperexcitability (Gibson et al., 2008; Goncalves et al., 2013). Specifically, spontaneously occurring UP states are $38-67 \%$ longer in Fmr1 ${ }^{K O}$ than in WT slices (Hays et al., 2011). Deletion of Fmr1 selectively in excitatory neurons mimics the prolonged UP states whereas knockdown of $\mathrm{mGluR}_{5}$ rescues the hyperexcitability in the $F m r 1^{K O}$ with no effect in WT (Hays et al., 2011). To determine if hyperexcitability was rescued in $F m r 1^{K O}$ mice by knockdown of App, we recorded UP states in $F m r 1^{K O} / A p p^{H E T}$ mice and littermate controls per previously described methods (Gibson et al., 2008). Briefly, Fmr1 $1^{H E T} / A p p^{H E T}$ females were bred with $A p p^{H E T}$ males to generate WT, Fmr1 ${ }^{K O}, A p p^{H E T}$ and $F m r 1^{K O} / A p p^{H E T}$ male littermates. Thalamocortical slices (400 $\mu \mathrm{m}$ ) from postnatal day 24-28 (P24-P28) males were transected parallel to the pia mater to remove the thalamus and midbrain, and spontaneously generated UP states were recorded in layer 4 of the somatosensory cortex. The increased duration of the UP states observed in the $F m r 1^{K O}$ was completely rescued in Fmr1 ${ }^{K O} / A P P^{H E T}$ mice (Figures 1A,B) where UP state duration decreased from $931 \pm 55$ milliseconds (ms) in $F m r 1^{K O}$ to $597 \pm$ $30 \mathrm{~ms}$ in $\mathrm{Fmrl}^{\mathrm{KO}} / \mathrm{APP} \mathrm{PET}^{\mathrm{H}},(\mathrm{p}<0.001)$. UP state duration was not significantly different between $A P P^{H E T}$ and WT slices suggesting that rescue was not a consequence of a general reduction in excitability due to lower APP levels.

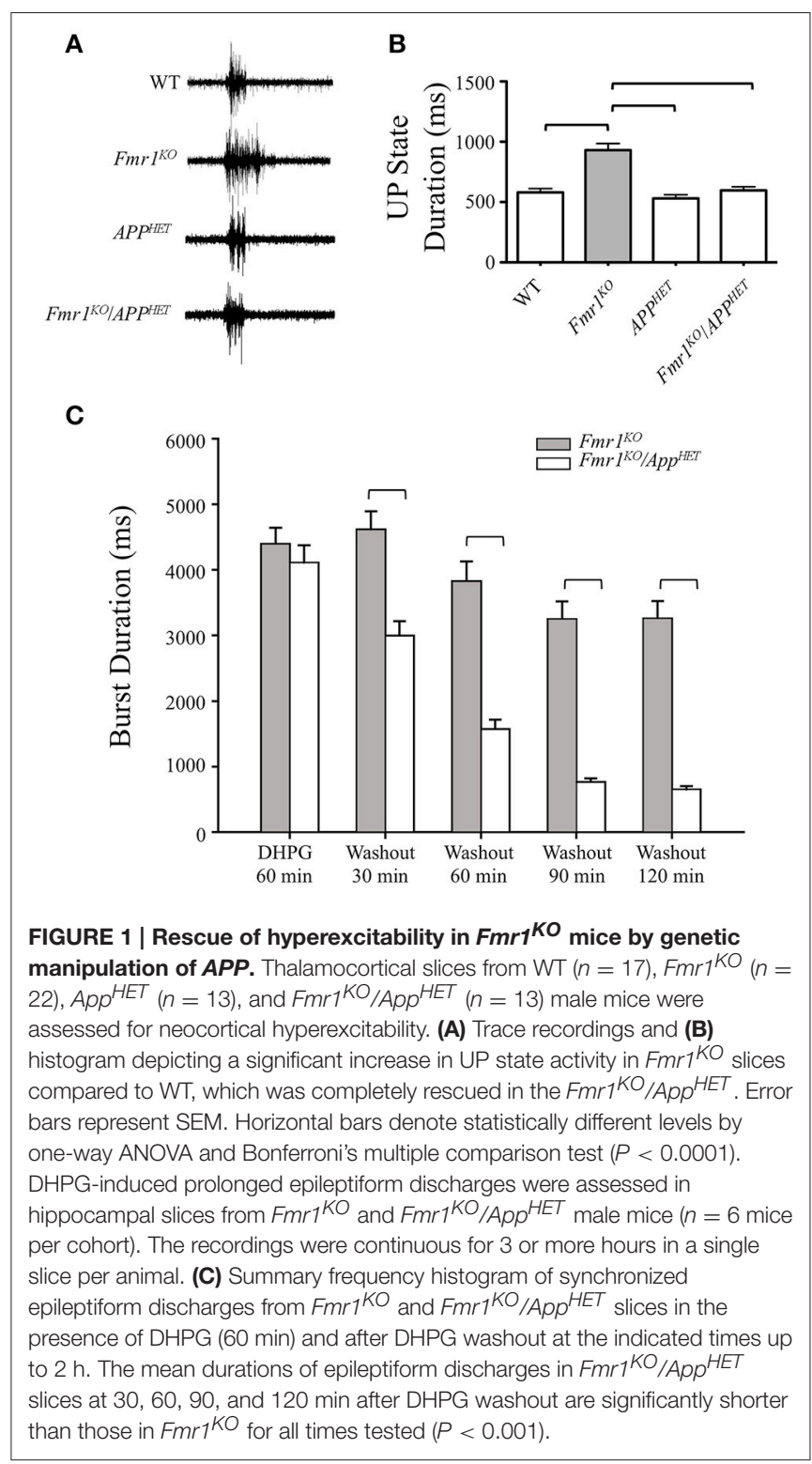


Hyperexcitability can also be evaluated in slices of the CA3 region of the hippocampus in $F m r 1^{K O}$ mice. Prolonged epileptic bursts can be induced by group $1 \mathrm{mGluR}$ agonists in both WT and $F m r 1^{K O}$ mice and with a GABAergic antagonist only in Fmr1 ${ }^{K O}$ (Chuang et al., 2005; Zhong et al., 2009). In WT slices, DHPG elicits short ( $\sim 500 \mathrm{~ms})$ synchronized discharges that gradually extend to reach an average duration of $4.4 \pm 0.14 \mathrm{~s}$ at $60 \mathrm{~min}$; and in untreated $F m r 1^{K O}$ slices, bicuculline elicits short $<1 \mathrm{~ms}$ synchronized discharges that progressively increase in duration over $60 \mathrm{~min}$ (average duration 2.3 ïĆś $0.13 \mathrm{~s}$ ) (Osterweil et al., 2013). These prolonged epileptiform discharges resemble the ictal discharges observed in the CA3 region in epilepsy (Merlin and Wong, 1997; Wong et al., 2004). The number and duration of ictal-like discharges were assessed by intracellular CA3 recordings in juvenile $F m r 1^{K O}$ and $F m r 1^{K O} / A p p^{H E T}$ slices in the presence of DHPG (60 min) and after DHPG washout for up to $2 \mathrm{~h}$ as previously described (Chuang et al., 2005) (Figure 1C, Supplementary Figure 1). In the presence of DHPG, a distinct population of ictal-like discharges (burst duration $>$ $1500 \mathrm{~ms}$ ) occurred in both $\mathrm{Fmr1} 1^{\mathrm{KO}}$ and $\mathrm{Fmr1} \mathrm{I}^{\mathrm{KO}} / \mathrm{Ap} \mathrm{p}^{\mathrm{HET}}$ slices. After DHPG washout, the ictal-like discharges remained distinct for the duration of the recording (up to $2 \mathrm{~h}$ post-DHPG washout) in the $F m r 1^{K O}$, but not in the Fmr1 ${ }^{K O} / A p p^{H E T}$ slices. Thus, a major difference between $F m r 1^{K O}$ and $F m r 1^{K O} / A p p^{H E T}$ slices is that while ictal-like discharges were transiently expressed in both genotypes, they were not maintained in the Fmr1 $1^{K O} / A p p^{H E T}$ upon termination of receptor stimulation. The seizure activity modeled in the hippocampal slice paradigm is congruent with the AGS phenotype observed in $F m r 1^{K O} / A p p^{H E T}$ mice where wild running and seizures are attenuated but not completely rescued to WT levels (Westmark et al., 2011). The two critical components of plasticity include the initiating factors required for induction of the modification and the downstream effectors that maintain expression of the enhanced response (Bianchi et al., 2012). Our data suggest that genetic reduction of App in the $F m r 1^{K O}$ background does not prevent the induction of seizure activity, but can attenuate progression; thus, APP appears to be a downstream effector that maintains hyperexcitability in the context of the $\mathrm{Fmrl}^{\mathrm{KO}}$.

The complete rescue of hyperexcitability in the neocortex compared to the partial rescue in the hippocampus in the $F m r 1^{K O} / A p p^{H E T}$ mice is in accord with studies in immature mice demonstrating that the hippocampus has a lower seizure threshold compared to neocortex (Abdelmalik et al., 2005). This could be due differential expression and/or activity of group 1 mGluRs $\left(\mathrm{mGluR}_{1}\right.$ and $\mathrm{mGluR}_{5}$ ) in the respective neurons under study. In fast spiking inhibitory neurons (neocortical slice model), $\mathrm{mGluR}_{1}$ is more highly expressed than $\mathrm{mGluR}_{5}$ (Sun et al., 2009); however reduced expression of $\mathrm{mGluR}_{5}$ or APP in the $F m r 1^{K O}$ completely rescues neocortical hyperexcitability whereas UP states are still longer in the $F m r 1^{K O}$ after treatment with the $\mathrm{mGluR}_{1}$ inhibitor LY367385 (Hays et al., 2011). These data suggest that $\mathrm{mGluR}_{5}$ is the critical group $1 \mathrm{mGluR}$ that modulates Fmr1-dependent hyperexcitability in the neocortex. Alternatively, in CA3 hippocampal neurons, both group 1 mGluR subtypes are involved in the induction and maintenance of mGluR-mediated bursts, but $\mathrm{mGluR}_{5}$ plays a greater role in the induction and $\mathrm{mGluR}_{1}$ in the maintenance of the prolonged epileptic bursts (Merlin, 2002). As burst duration but not induction are rescued in the $F m r 1^{K O} / A P P^{H E T}$, these data suggest that the hyperexcitability elicited by elevated APP expression in the $F m r 1^{K O}$ CA3 region is dependent on $\mathrm{mGluR}_{1}$.

Synaptic dysfunction occurs when the appropriate balance of excitation and inhibition $(\mathrm{E} / \mathrm{I})$ in neural circuits is not maintained (Gatto and Broadie, 2010). The absence of FMRP during postnatal development results in an $\mathrm{E} / \mathrm{I}$ imbalance dominated by excitation. Our results demonstrate that E/I balance is predominantly restored when APP expression is reduced to WT levels in the $F m r 1^{K O}$. Thus, APP plays a critical role in modulating excitability. The other half of E/I balance is the inhibitory feedback on circuits. FMRP normally binds to multiple $\mathrm{GABA}_{A} \mathrm{R}$ mRNAs, and their expression is decreased in juvenile $F m r 1^{K O}$ (Braat et al., 2015) resulting in delay of the developmental GABA switch in $F m r 1^{K O}$ (He et al., 2014). Selective deletion of Fmr1 in inhibitory neurons has no effect on prolonged UP states suggesting that impaired $\mathrm{GABA}_{A} \mathrm{R}$ signaling in FXS does not account for increased hyperexcitability in the neocortex (Hays et al., 2011). Conversely, a competitive antagonist of $\mathrm{GABA}_{A} \mathrm{R}$, bicuculline, elicits epileptiform discharges in the CA3 region of the hippocampus (Osterweil et al., 2013). These findings suggest that inhibitory feedback is differentially regulated in the neocortex and hippocampus in $F m r 1^{K O}$. Overall, the neocortical hyperexcitability and hippocampal epileptiform discharge slice models share the features of prolonged activity states and dependence on $\mathrm{mGluR}_{5}, \mathrm{FMRP}$, and APP, but differ in induction mode (neocortical slices exhibit baseline excitation vs. hippocampal slices require pharmacological stimulation), inhibitory feedback (hippocampal slices are dependent of $\mathrm{GABA}_{A} \mathrm{R}$ ), and protein synthesis requirements (CA3 bursts require extracellular signal-regulated kinase (ERK)1/2 activation and new protein synthesis) (Zhao et al., 2004; Chuang et al., 2005; Hays et al., 2011).

\section{A MODEL FOR AN APP-INDUCED SHORT CIRCUIT IN FRAGILE $X$}

Regarding possible mechanisms for APP-mediated hyperexcitability, (Westmark, 2013) APP or a metabolite could interfere with cell surface receptor activation. For example, $A \beta$ oligomers cause redistribution of $\mathrm{mGluR}_{5}$ to synapses (Renner et al., 2010) and trigger multiple distinct signaling events through $\mathrm{mGluR}_{5}$ /prion protein complexes (Um et al., 2013; Hu et al., 2014; Haas and Strittmatter, 2016). In neurons that overexpress APP, A $\beta$ depresses excitatory synaptic transmission (Kamenetz et al., 2003). In $F m r 1^{K O}$ mice, $A \beta$ levels are elevated in older mice but reduced in juvenile mice compared to WT controls (Westmark et al., 2011; Pasciuto et al., 2015). Thus, increased $\alpha$-secretase and/or decreased BACE1 processing during postnatal development could result in decreased $A \beta$ levels and increased synaptic transmission (Jin and Warren, 2000) Altered APP expression could affect scaffolding protein interactions at the postsynaptic density. For example, APP co-immunoprecipitates 
with Homer2 and Homer3 (Parisiadou et al., 2008). These scaffolding proteins inhibit APP processing, reduce cell surface APP expression, and prevent maturation of BACE1 (Parisiadou et al., 2008). Uncoupled Homer1-mGluR ${ }_{5}$ interactions underlie $F m r 1^{K O}$ phenotypes, and genetic deletion of Homerla rescues prolonged UP states in Fmr1 ${ }^{K O}$ mice similar to the complete rescue observed herein in the $F m r 1^{K O} / A P P^{H E T}$ mice (Ronesi et al., 2012). APP does not co-immunoprecipitate with Homer1 (Parisiadou et al., 2008); however, A $\beta$ induces disassembly of Homer1b and Shank1 clusters (Roselli et al., 2009). (Westmark and Malter, 2012) APP or metabolites could alter the activity of intracellular signaling pathways such as ERK and mTOR (Young et al., 2009; Ma et al., 2010; Caccamo et al., 2011; Chasseigneaux et al., 2011; Pasciuto et al., 2015). Both of these pathways play pivotal roles in FXS pathology (Osterweil et al., 2010; Hoeffer et al., 2012). And Westmark and Malter (2007) APP metabolites could function in feedback loops to regulate the aforementioned pathways or even the transcription of the APP and APP processing enzymes. $\mathrm{A} \beta$ binds to the promoter regions of the APP and BACE1 genes and may function as a transcription factor to regulate its own production and/or processing (Bailey et al., 2011). Thus, there are numerous molecular junctures where altered expression of APP or metabolites could interfere with synaptic function and lead to a hyperexcitable circuit.

Overall, these data suggest a model whereby mGluR $_{5}$ inhibitors act as a circuit breaker, FMRP as an automatic transfer switch and APP as a rheostat in a circuit that controls hyperexcitability (Figure 2 ). The $m G l u R_{5}$ circuit breaker: Genetic reduction of $\mathrm{mGluR}_{5}$ in the $F m r 1^{K O}$ mouse rescues plasticity (ocular dominance plasticity, neocortical hyperexcitability), dendritic spines (density on cortical pyramidal neurons), protein synthesis, behavior (inhibitory avoidance extinction), and AGS (Dolen et al., 2007; Hays et al., 2011). Pharmaceutical inhibition of $\mathrm{mGluR}_{5}$ likewise rescues numerous $F m r 1^{K O}$ phenotypes (Michalon et al., 2012, 2014). Thus, inhibiting mGluR $_{5}$ appears to break a circuit that mediates hyperexcitability in the $F m r 1^{K O}$ mouse. The FMRP automatic transfer switch: $\mathrm{mGluR}_{5}$ activation causes a rapid dephosphorylation of FMRP, which permits protein synthesis (Ceman et al., 2003; Narayanan et al., 2007), as well as a biphasic change in FMRP levels (initial decrease followed by increase) (Zhao et al., 2011). Thus, FMRP appears to function as an automatic transfer switch downstream of GluR $_{5}$ to control protein synthesis in response to receptor activation. In FXS models, loss of the FMRP switch that modulates mGluR $_{5}$ signaling permits a constitutively-on circuit. The APP rheostat: Born and colleagues demonstrated that juvenile overexpression of APP contributes to sharp wave EEG discharges in APP transgenic mice, and proposed that APP expression functions as a rheostat that regulates synaptic balance in the brain (Born et al., 2014). We have observed that both over- and underexpression of APP increases seizure propensity in juvenile $F m r 1^{K O}$ mice suggesting that tight regulation of this protein may be necessary to mitigate hyperexcitability in FXS (Westmark et al., 2010, 2011). Genetic reduction of APP in Fmr1 ${ }^{K O}$ mice rescues plasticity (mGluR-LTD, neocortical hyperexcitability, epileptiform discharge duration but not induction), dendritic spines (percent mature spines but not dendritic spine length), protein synthesis, behavior (open field, marble burying), and AGS (Westmark et al., 2011; Pasciuto et al., 2015). The partial rescue of dendritic spines and epileptiform discharges in the $F m r 1^{K O} / A P P^{H E T}$ suggests that APP is necessary but not sufficient to maintain synaptic homeostasis. Thus, in the context of WT mice, an APP variable resistor is capable of maintaining an appropriate E/I balance, but in $F m r 1^{K O}$ and some APP transgenic mice, excess APP appears to cause a short circuit through overload of the APP rheostat resulting in hyperexcitability. Likewise, complete loss of APP would bypass the APP rheostat. $F m r 1^{K O} / A p p^{K O}$ mice exhibit an extremely strong AGS phenotype (97\%, $n=36$ mice) (Westmark et al., 2013a), which is not observed in $A p p^{K O}$ mice ( $11 \%, n=36$ mice). These data suggest that exacerbated hyperexcitability is a result of the combined loss of both FMRP and APP.

APP and metabolites play key roles in regulating synaptic activity with both $\mathrm{A} \beta$ and $\mathrm{SAPP} \alpha$ implicated in positive feedback loops that facilitate $\mathrm{mGluR}_{5}$ signaling (Casley et al., 2009; Renner et al., 2010; Ferreira and Klein, 2011; Westmark et al., 2011, 2013b; Pasciuto et al., 2015). Thus, the APP rheostat may provide a graded response to $\mathrm{mGluR}_{5}$ activation through feedback loops involving amyloidogenic and non-amyloidogenic secretase processing. We found that AGS are attenuated in $F m r 1^{K O}$ mice with BACE1 inhibitor treatment (Supplementary Figure 2). Prox and colleagues found that seizures are increased in the ADAM10 conditional knockout mouse (loss of $\alpha$ secretase processing) (Prox et al., 2013). The effect of sAPP $\alpha$ overexpression on hyperexcitability, which could be studied in $\operatorname{TgAPP} \alpha\left(\right.$ Bailey et al., 2013) and TgAPP $\alpha / F m r 1^{K O}$ mice, remains to be determined. Thus, multiple APP fragments may play roles in hyperexcitability and seizure susceptibility. A caveat to this model is that over-expression of APP alone is not sufficient to increase seizure propensity in either WT or $F m r 1^{K O}$ mice. We tested seizures in two alternative Alzheimer's disease mouse models, R1.40 and J20, which exhibit elevated APP expression (Lamb et al., 1997; Mucke et al., 2000). Neither strain exhibited a strong AGS phenotype (Supplementary Figures 3,4) in contrast to Tg2576 and Ts65Dn (Westmark et al., 2010). A genetic cross of J20 with $F m r 1^{K O}$ mice that produced mice over-expressing human APP in the context of the $F m r 1^{K O}$ background did not result in exacerbated AGS rates in comparison to $F m r 1^{K O}$ unlike the FRAXAD mice (cross of Tg2576 with $F m r 1^{K O}$ ) (Westmark et al., 2010). The inclusion of flanking sequences in the transgenic constructs used for the R1.40 and J20 mice are expected to affect posttranscriptional regulation of the APP gene, which could alter the temporal and spatial expression of APP and metabolites and thus their contribution to seizure threshold. Of note, Fmr1 $1^{H E T} / \mathrm{J} 20$ female mice exhibited a $50 \%$ wild running rate, which was significantly higher than WT, Fmr1 $1^{\text {HET }}$ and J20 controls, supporting the assertion that APP works in synergy with FMRP to regulate hyperexcitability (Supplementary Figure 4). This synergistic effect is also observed in mGluR-LTD studies where loss of FMRP and APP modulate synaptic transmission in opposite directions (Westmark et al., 2011). The Fmr1 ${ }^{K O} / A P P^{H E T}$ mice used herein were a constitutive $A p p$ knockdown. It remains to be determined how conditional knockdown of App during development affects Fmr1 phenotypes. 


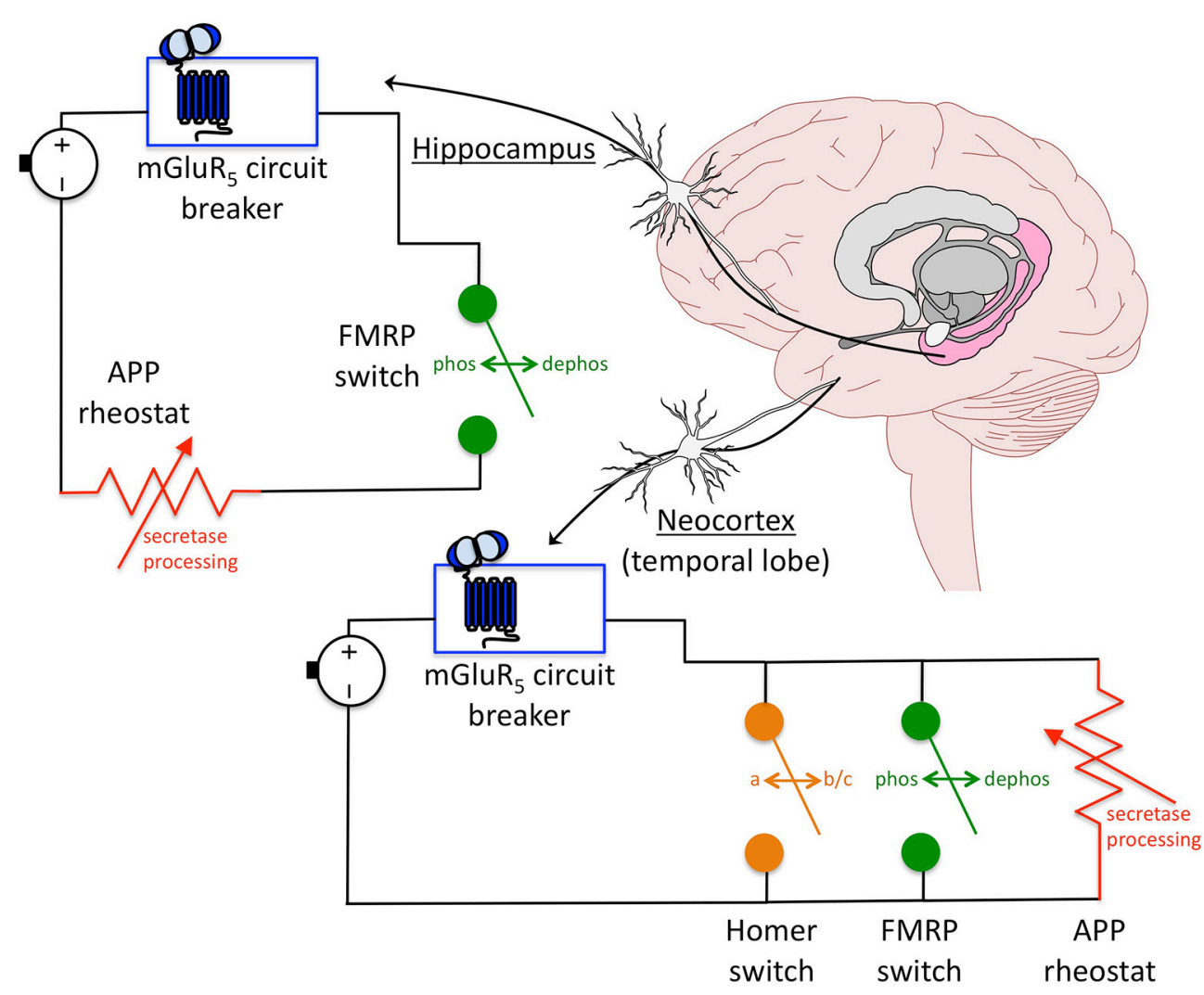

FIGURE 2 | Model for an APP-induced short circuit in FXS. APP acts as a rheostat (i.e., variable resistor, dimmer switch) in a circuit where mGluR 5 inhibitors are a circuit breaker and FMRP is an automatic transfer switch that regulate neuronal excitability. The FMRP switch is dependent on a rapid dephosphorylation reaction in response to mGluR $_{5}$ activation. In the absence of FMRP, the circuit is constitutively on. In the presence of mGluR 5 inhibitors, the circuit is shut down. The downstream APP circuitry appears to be wired differently dependent on brain region. In the neocortex, knockdown of individual proteins including mGluR 5 , Homer and APP completely rescues excitability levels suggesting that these components are arranged in a parallel circuit whereby there is more than one continuous signaling pathway between mGluR $_{5}$ activation and excitability output. Rescue of any one of the parallel components is sufficient to restore synaptic homeostasis. In the hippocampus, ictal burst duration, but not induction, is rescued in Fmr1 ${ }^{K O} / A p p H E T$ slices in response to DHPG treatment. This incomplete rescue suggests that APP and FMRP are wired in series downstream of mGluR $_{5}$, and that the APP rheostat is overloaded in the absence of FMRP resulting in a short circuit. This model has important implications for therapeutic development and suggests that APP should be considered as a drug target for FXS as part of a multi-drug therapeutic strategy.

\section{RELEVANCE TO THERAPEUTIC DEVELOPMENT}

All major $F m r 1^{K O}$ phenotypes can be corrected by inhibition or knockdown of $\mathrm{mGluR}_{5}$ in mice; however, neural circuitry is likely more complicated in humans and it may be necessary to employ pharmaceutical cocktails for disease treatment. Drugs under study for FXS such as acamprosate, AFQ056, donepezil, ganaxolone, lithium, lovastatin, memantine, minocycline and sertraline exhibit on- and/or off-site effects that are expected to modulate APP, A $\beta$, BACE1, and/or ADAM10 (Westmark et al., 2013b). Targeting APP and metabolites in FXS may allow fine tuning of excitability levels as part of a multi-drug therapeutic approach. Both amyloidogenic and non-amyloidogenic therapies have been proposed to treat FXS (Westmark et al., 2013b; Pasciuto et al., 2015). Both amyloidogenic $\left(\mathrm{A} \beta_{1-42}\right)$ and non-amyloidogenic $(\mathrm{APP} \alpha)$ metabolites of APP stimulate phosphorylation of ERK and modulate synthesis of multiple synaptic proteins predicted to be regulated through $\mathrm{mGluR}_{5} / \mathrm{FMRP}$ and to contribute to altered synaptic plasticity (Westmark et al., 2011; Pasciuto et al., 2015). Thus, it may be necessary to simultaneously modulate both $\alpha$ - and $\beta$-secretase processing to attain homeostatic levels of APP metabolites and rescue hyperexcitability in FXS.

\section{AUTHOR CONTRIBUTIONS}

CW, JG, KH, RW conceived and designed the experiments. CW, SC, SH, MF, BR, PW acquired data. CW, SC, $\mathrm{SH}$, JG, KH, RW interpreted data. CW drafted the manuscript.

\section{FUNDING}

This work was funded by FRAXA Research Foundation and NIH R21AG044714 (CW), and NIH 1R01HD056370 (JG). 


\section{ACKNOWLEDGMENTS}

The authors thank the Research Animal Resources Centers (RARC) staffs at the University of Wisconsin, the State University of New York Downstate Medical Center and the University of Texas Southwestern for expert animal care and assistance with transport between facilities. All mouse procedures were performed in accordance with NIH guidelines and approved University of Wisconsin-Madison, State University of New York

\section{REFERENCES}

Abdelmalik, P. A., Burnham, W. M., and Carlen, P. L. (2005). Increased seizure susceptibility of the hippocampus compared with the neocortex of the immature mouse brain in vitro. Epilepsia 46, 356-366. doi: 10.1111/j.0013-9580.2005.34204.x

Bailey, A. R., Hou, H., Song, M., Obregon, D. F., Portis, S., Barger, S., et al. (2013). GFAP expression and social deficits in transgenic mice overexpressing human sAPPalpha. Glia 61, 1556-1569. doi: 10.1002/glia.22544

Bailey, J. A., Maloney, B., Ge, Y. W., and Lahiri, D. K. (2011). Functional activity of the novel Alzheimer's amyloid beta-peptide interacting domain (AbetaID) in the APP and BACE1 promoter sequences and implications in activating apoptotic genes and in amyloidogenesis. Gene 488, 13-22. doi: 10.1016/j.gene.2011.06.017

Berry-Kravis, E. (2002). Epilepsy in fragile X syndrome. Dev. Med. Child Neurol. 44, 724-728. doi: 10.1111/j.1469-8749.2002.tb00277.x

Berry-Kravis, E., Hessl, D., Abbeduto, L., Reiss, A. L., Beckel-Mitchener, A., Urv, T. K., et al. (2013). Outcome measures for clinical trials in fragile x syndrome. J. Dev. Behav. Pediatr. 34, 508-522. doi: 10.1097/DBP.0b013e31829d1f20

Bianchi, R., Wong, R. K. S., and Merlin, L. R. (2012). "Glutamate receptors in epilepsy: group I mGluR-mediated epileptogenesis," in Jasper's Basic Mechanisms of the Epilepsies, 4th Edn., eds J. L. Noebels, M. Avoli, M. A. Rogawski, R. W. Olsen, and A. V. Delgado-Escueta (Bethesda, MD: Oxford University Press). doi: 10.1093/med/9780199746545.003.0011

Born, H. A., Kim, J. Y., Savjani, R. R., Das, P., Dabaghian, Y. A., Guo, Q., et al. (2014). Genetic suppression of transgenic APP rescues Hypersynchronous network activity in a mouse model of Alzheimer's disease. J. Neurosci. 34, 3826-3840. doi: 10.1523/JNEUROSCI.5171-13.2014

Braat, S., D'Hulst, C., Heulens, I., De Rubeis, S., Mientjes, E., Nelson, D. L., et al. (2015). The GABAA receptor is an FMRP target with therapeutic potential in fragile X syndrome. Cell Cycle 14, 2985-2995. doi: $10.4161 / 15384101.2014 .989114$

Caccamo, A., Maldonado, M. A., Majumder, S., Medina, D. X., Holbein, W., Magri, A., et al. (2011). Naturally secreted amyloid-beta increases mammalian target of rapamycin (mTOR) activity via a PRAS40-mediated mechanism. J. Biol. Chem. 286, 8924-8932. doi: 10.1074/jbc.M110.180638

Casley, C. S., Lakics, V., Lee, H. G., Broad, L. M., Day, T. A., Cluett, T., et al. (2009). Up-regulation of astrocyte metabotropic glutamate receptor 5 by amyloid- $\beta$ peptide. Brain Res. 1260, 65-75. doi: 10.1016/j.brainres.2008.12.082

Ceman, S., O'Donnell, W. T., Reed, M., Patton, S., Pohl, J., and Warren, S. T. (2003). Phosphorylation influences the translation state of FMRPassociated polyribosomes. Hum. Mol. Genet. 12, 3295-3305. doi: 10.1093/hmg/ $\operatorname{ddg} 350$

Chasseigneaux, S., Dinc, L., Rose, C., Chabret, C., Coulpier, F., Topilko, P., et al. (2011). Secreted amyloid precursor protein beta and secreted amyloid precursor protein alpha induce axon outgrowth in vitro through Egrl signaling pathway. PLoS ONE 6:e16301. doi: 10.1371/journal.pone.0016301

Chen, L., and Toth, M. (2001). Fragile X mice develop sensory hyperreactivity to auditory stimuli. Neuroscience 103, 1043-1050. doi: 10.1016/S0306-4522(01)00036-7

Chuang, S. C., Zhao, W., Bauchwitz, R., Yan, Q., Bianchi, R., and Wong, R. K. (2005). Prolonged epileptiform discharges induced by altered group I metabotropic glutamate receptor-mediated synaptic responses in hippocampal slices of a fragile X mouse model. J. Neurosci. 25, 8048-8055. doi: 10.1523/JNEUROSCI.1777-05.2005
Downstate Medical Center and University of Texas Southwestern Medical Center animal care protocols administered through their RARC.

\section{SUPPLEMENTARY MATERIAL}

The Supplementary Material for this article can be found online at: http://journal.frontiersin.org/article/10.3389/fnmol. 2016.00147/full\#supplementary-material

Del Vecchio, R. A., Gold, L. H., Novick, S. J., Wong, G., and Hyde, L. A. (2004). Increased seizure threshold and severity in young transgenic CRND8 mice. Neurosci. Lett. 367, 164-167. doi: 10.1016/j.neulet.2004.05.107

Dolen, G., Osterweil, E., Rao, B. S., Smith, G. B., Auerbach, B. D., Chattarji, S., et al. (2007). Correction of Fragile X Syndrome in Mice. Neuron 56, 955-962. doi: 10.1016/j.neuron.2007.12.001

Erickson, C. A., Ray, B., Maloney, B., Wink, L. K., Bowers, K., Schaefer, T. L., et al. (2014). Impact of acamprosate on plasma amyloid-beta precursor protein in youth: a pilot analysis in fragile $\mathrm{X}$ syndrome-associated and idiopathic autism spectrum disorder suggests a pharmacodynamic protein marker. J. Psychiatr. Res. 59, 220-228. doi: 10.1016/j.jpsychires.2014.07.011

Ferreira, S. T., and Klein, W. L. (2011). The Abeta oligomer hypothesis for synapse failure and memory loss in Alzheimer's disease. Neurobiol. Learn. Mem. 96, 529-543. doi: 10.1016/j.nlm.2011.08.003

Gatto, C. L., and Broadie, K. (2010). Genetic controls balancing excitatory and inhibitory synaptogenesis in neurodevelopmental disorder models. Front. Synaptic Neurosci. 2:4. doi: 10.3389/fnsyn.2010.00004

Gibson, J. R., Bartley, A. F., Hays, S. A., and Huber, K. M. (2008). Imbalance of neocortical excitation and inhibition and altered UP states reflect network hyperexcitability in the mouse model of fragile X syndrome. J. Neurophysiol. 100, 2615-2626. doi: 10.1152/jn.90752.2008

Goncalves, J. T., Anstey, J. E., Golshani, P., and Portera-Cailliau, C. (2013). Circuit level defects in the developing neocortex of Fragile X mice. Nat. Neurosci. 16, 903-909. doi: 10.1038/nn.3415

Haas, L. T., and Strittmatter, S. M. (2016). Oligomers of amyloid beta prevent physiological activation of the cellular prion protein-metabotropic glutamate receptor 5 complex by glutamate in Alzheimer disease. J. Biol. Chem. 291, 17112-17121. doi: 10.1074/jbc.M116.720664

Hays, S. A., Huber, K. M., and Gibson, J. R. (2011). Altered neocortical rhythmic activity states in Fmr1 KO mice are due to enhanced mGluR5 signaling and involve changes in excitatory circuitry. J. Neurosci. 31, 14223-14234. doi: 10.1523/JNEUROSCI.3157-11.2011

He, Q., Nomura, T., Xu, J., and Contractor, A. (2014). The developmental switch in GABA polarity is delayed in fragile X mice. J. Neurosci. 34, 446-450. doi: 10.1523/JNEUROSCI.4447-13.2014

Hoeffer, C. A., Sanchez, E., Hagerman, R. J., Mu, Y., Nguyen, D. V., Wong, H., et al. (2012). Altered mTOR signaling and enhanced CYFIP2 expression levels in subjects with fragile X syndrome. Genes Brain Behav. 11, 332-341. doi: 10.1111/j.1601-183X.2012.00768.x

Hu, N. W., Nicoll, A. J., Zhang, D., Mably, A. J., O’Malley, T., Purro, S. A., et al. (2014). mGlu5 receptors and cellular prion protein mediate amyloidbeta-facilitated synaptic long-term depression in vivo. Nat. Commun. 5:3374. doi: $10.1038 /$ ncomms4374

Jin, P., and Warren, S. T. (2000). Understanding the molecular basis of fragile X syndrome. Hum. Mol. Genet. 9, 901-908. doi: 10.1093/hmg/9.6.901

Kamenetz, F., Tomita, T., Hsieh, H., Seabrook, G., Borchelt, D., Iwatsubo, T., et al. (2003). APP processing and synaptic function. Neuron 37, 925-937. doi: 10.1016/S0896-6273(03)00124-7

Kobayashi, D., Zeller, M., Cole, T., Buttini, M., McConlogue, L., Sinha, S., et al. (2008). BACE1 gene deletion: impact on behavioral function in a model of Alzheimer's disease. Neurobiol. Aging 29, 861-873. doi: 10.1016/j.neurobiolaging.2007.01.002

Lalonde, R., Dumont, M., Staufenbiel, M., and Strazielle, C. (2005). Neurobehavioral characterization of APP23 transgenic mice with the SHIRPA primary screen. Behav. Brain Res. 157, 91-98. doi: 10.1016/j.bbr.2004.06.020 
Lamb, B. T., Call, L. M., Slunt, H. H., Bardel, K. A., Lawler, A. M., Eckman, C. B., et al. (1997). Altered metabolism of familial Alzheimer's disease-linked amyloid precursor protein variants in yeast artificial chromosome transgenic mice. Hum. Mol. Genet. 6, 1535-1541. doi: 10.1093/hmg/6.9.1535

Ma, T., Hoeffer, C. A., Capetillo-Zarate, E., Yu, F., Wong, H., Lin, M. T., et al. (2010). Dysregulation of the mTOR pathway mediates impairment of synaptic plasticity in a mouse model of Alzheimer's disease. PLoS ONE 5:e12845. doi: 10.1371/journal.pone.0012845

Merlin, L. R. (2002). Differential roles for mGluR1 and mGluR5 in the persistent prolongation of epileptiform bursts. J. Neurophysiol. 87, 621-625.

Merlin, L. R., and Wong, R. K. (1997). Role of group I metabotropic glutamate receptors in the patterning of epileptiform activities in vitro. J. Neurophysiol. 78, 539-544

Michalon, A., Bruns, A., Risterucci, C., Honer, M., Ballard, T. M., Ozmen, L., et al. (2014). Chronic metabotropic glutamate receptor 5 inhibition corrects local alterations of brain activity and improves cognitive performance in fragile $\mathrm{X}$ mice. Biol. Psychiatry 75, 189-197. doi: 10.1016/j.biopsych.2013.05.038

Michalon, A., Sidorov, M., Ballard, T. M., Ozmen, L., Spooren, W., Wettstein, J. G., et al. (2012). Chronic pharmacological mGlu5 inhibition corrects fragile $\mathrm{X}$ in adult mice. Neuron 74, 49-56. doi: 10.1016/j.neuron.2012.03.009

Minkeviciene, R., Rheims, S., Dobszay, M. B., Zilberter, M., Hartikainen, J., Fülöp, L., et al. (2009). Amyloid beta-induced neuronal hyperexcitability triggers progressive epilepsy. J. Neurosci. 29, 3453-3462. doi: 10.1523/JNEUROSCI. 5215-08.2009

Moechars, D., Lorent, K., De Strooper, B., Dewachter, I., and Van Leuven, F. (1996). Expression in brain of amyloid precursor protein mutated in the alphasecretase site causes disturbed behavior, neuronal degeneration and premature death in transgenic mice. EMBO J. 15, 1265-1274.

Mucke, L., Masliah, E., Yu, G. Q., Mallory, M., Rockenstein, E. M., Tatsuno, G., et al. (2000). High-level neuronal expression of Abeta 1-42 in wild-type human amyloid protein precursor transgenic mice: synaptotoxicity without plaque formation. J. Neurosci. 20, 4050-4058.

Narayanan, U., Nalavadi, V., Nakamoto, M., Pallas, D. C., Ceman, S., Bassell, G. J., et al. (2007). FMRP phosphorylation reveals an immediate-early signaling pathway triggered by group I mGluR and mediated by PP2A. J. Neurosci. 27, 14349-14357. doi: 10.1523/JNEUROSCI.2969-07.2007

Osterweil, E. K., Chuang, S. C., Chubykin, A. A., Sidorov, M., Bianchi, R., Wong, R. K., et al. (2013). Lovastatin corrects excess protein synthesis and prevents epileptogenesis in a mouse model of fragile x syndrome. Neuron 77, 243-250. doi: 10.1016/j.neuron.2012.01.034

Osterweil, E. K., Krueger, D. D., Reinhold, K., and Bear, M. F. (2010). Hypersensitivity to mGluR5 and ERK1/2 leads to excessive protein synthesis in the hippocampus of a mouse model of fragile X syndrome. J. Neurosci. 30, 15616-15627. doi: 10.1523/JNEUROSCI.3888-10.2010

Palop, J. J., Chin, J., Roberson, E. D., Wang, J., Thwin, M. T., Bien-Ly, N., et al. (2007). Aberrant excitatory neuronal activity and compensatory remodeling of inhibitory hippocampal circuits in mouse models of Alzheimer's disease. Neuron 55, 697-711. doi: 10.1016/j.neuron.2007.07.025

Parisiadou, L., Bethani, I., Michaki, V., Krousti, K., Rapti, G., and Efthimiopoulos, S. (2008). Homer2 and Homer3 interact with amyloid precursor protein and inhibit Abeta production. Neurobiol. Dis. 30, 353-364. doi: 10.1016/j.nbd.2008.02.004

Pasciuto, E., Ahmed, T., Wahle, T., Gardoni, F., D’Andrea, L., Pacini, L., et al. (2015). Dysregulated ADAM10-mediated processing of APP during a critical time window leads to synaptic deficits in fragile X syndrome. Neuron 87, 382-398. doi: 10.1016/j.neuron.2015.06.032

Prox, J., Bernreuther, C., Altmeppen, H., Grendel, J., Glatzel, M., D’Hooge, R., et al. (2013). Postnatal disruption of the disintegrin/metalloproteinase ADAM10 in brain causes epileptic seizures, learning deficits, altered spine morphology, and defective synaptic functions. J. Neurosci. 33, 12915-12928. doi: 10.1523/jneurosci.5910-12.2013

Ray, B., Sokol, D. K., Maloney, B., and Lahiri, D. K. (2016). Finding novel distinctions between the sAPPalpha-mediated anabolic biochemical pathways in Autism Spectrum Disorder and Fragile X Syndrome plasma and brain tissue. Sci. Rep. 6:26052. doi: 10.1038/srep26052

Renner, M., Lacor, P. N., Velasco, P. T., Xu, J., Contractor, A., Klein, W. L., et al. (2010). Deleterious effects of amyloid beta oligomers acting as an extracellular scaffold for mGluR5. Neuron 66, 739-754. doi: 10.1016/j.neuron.2010. 04.029
Ronesi, J. A., Collins, K. A., Hays, S. A., Tsai, N.-P., Guo, W., Birnbaum, S. G., et al (2012). Disrupted Homer scaffolds mediate abnormal mGluR5 function in a mouse model of fragile X syndrome. Nat. Neurosci. 15, 431-440. doi: 10.1038/ nn. 3033

Roselli, F., Hutzler, P., Wegerich, Y., Livrea, P., and Almeida, O. F. (2009). Disassembly of shank and homer synaptic clusters is driven by soluble betaamyloid(1-40) through divergent NMDAR-dependent signalling pathways. PLoS ONE 4:e6011. doi: 10.1371/journal.pone.0006011

Sanchez, P. E., Zhu, L., Verret, L., Vossel, K. A., Orr, A. G., Cirrito, J. R., et al. (2012). Levetiracetam suppresses neuronal network dysfunction and reverses synaptic and cognitive deficits in an Alzheimer's disease model. Proc. Natl. Acad. Sci. U.S.A. 109, E2895-E2903. doi: 10.1073/pnas.1121081109

Sokol, D. K., Chen, D., Farlow, M. R., Dunn, D. W., Maloney, B., Zimmer, J. A., et al. (2006). High levels of Alzheimer beta-amyloid precursor protein (APP) in children with severely autistic behavior and aggression. J. Child Neurol. 21, 444-449.

Steinbach, J. P., Müller, U., Leist, M., Li, Z. W., Nicotera, P., and Aguzzi, A. (1998). Hypersensitivity to seizures in beta-amyloid precursor protein deficient mice. Cell Death Differ. 5, 858-866. doi: 10.1038/sj.cdd.4400391

Sun, Q. Q., Zhang, Z., Jiao, Y., Zhang, C., Szabo, G., and Erdelyi, F. (2009). Differential metabotropic glutamate receptor expression and modulation in two neocortical inhibitory networks. J. Neurophysiol. 101, 2679-2692. doi: 10.1152/jn.90566.2008

Tranfaglia, M. R. (2011). The psychiatric presentation of fragile $\mathrm{x}$ : evolution of the diagnosis and treatment of the psychiatric comorbidities of fragile $\mathrm{X}$ syndrome. Dev. Neurosci. 33, 337-348. doi: 10.1159/000329421

Um, J. W., Kaufman, A. C., Kostylev, M., Heiss, J. K., Stagi, M., Takahashi, H., et al. (2013). Metabotropic glutamate receptor 5 is a coreceptor for Alzheimer Abeta oligomer bound to cellular prion protein. Neuron 79, 887-902. doi: 10.1016/j.neuron.2013.06.036

Westmark, C. J. (2013). What's hAPPening at synapses? The role of amyloid $\beta$ protein precursor and beta-amyloid in neurological disorders. Mol. Psychiatry 18, 425-434. doi: $10.1038 / \mathrm{mp} .2012 .122$

Westmark, C. J., Berry-Kravis, E. M., Ikonomidou, C., Yin, J. C., and Puglielli, L. (2013b). Developing BACE-1 inhibitors for FXS. Front. Cell. Neurosci. 7:77. doi: $10.3389 /$ fncel.2013.00077

Westmark, C. J., and Malter, J. S. (2007). FMRP mediates mGluR5dependent translation of amyloid precursor protein. PLoS Biol. 5:e52. doi: 10.1371/journal.pbio.0050052

Westmark, C. J., and Malter, J. S. (2012). The regulation of A $\beta P P$ expression by RNA-binding proteins. Ageing Res. Rev. 11, 450-459. doi: 10.1016/j.arr.2012.03.005

Westmark, C. J., Sokol, D. K., Maloney, B., and Lahiri, D. K. (2016). Novel roles of amyloid-beta precursor protein metabolites in fragile X syndrome an autism. Mol. Psychiatry 21, 1333-1341. doi: 10.1038/mp.2016.134

Westmark, C. J., Westmark, P. R., Beard, A. M., Hildebrandt, S. M., and Malter, J. S. (2008). Seizure susceptibility and mortality in mice that over-express amyloid precursor protein. Int. J. Clin. Exp. Pathol. 1, 157-168.

Westmark, C. J., Westmark, P. R., and Malter, J. S. (2010). Alzheimer's disease and Down syndrome rodent models exhibit audiogenic seizures. J. Alzheimers. Dis. 20, 1009-1013. doi: 10.3233/JAD-2010-100087

Westmark, C. J., Westmark, P. R., and Malter, J. S. (2013a). Soy-based diet exacerbates seizures in mouse models of neurological disease. J. Alzheimers. Dis. 33, 797-805. doi: 10.3233/JAD-2012-121426

Westmark, C. J., Westmark, P. R., O’Riordan, K. J., Ray, B. C., Hervey, C. M., Salamat, M. S., et al. (2011). Reversal of Fragile X Phenotypes by Manipulation of AbetaPP/Abeta Levels in Fmr1 Mice. PLoS ONE 6:e26549. doi: 10.1371/journal.pone.0026549

Wong, R. K., Chuang, S. C., and Bianchi, R. (2004). Plasticity mechanisms underlying mGluR-induced epileptogenesis. Adv. Exp. Med. Biol. 548, 69-75. doi: 10.1007/978-1-4757-6376-8 5

Young, K. F., Pasternak, S. H., and Rylett, R. J. (2009). Oligomeric aggregates of amyloid beta peptide 1-42 activate ERK/MAPK in SHSY5Y cells via the alpha7 nicotinic receptor. Neurochem. Int. 55, 796-801. doi: 10.1016/j.neuint.2009.08.002

Zhao, W., Bianchi, R., Wang, M., and Wong, R. K. (2004). Extracellular signalregulated kinase $1 / 2$ is required for the induction of group I metabotropic glutamate receptor-mediated epileptiform discharges. J. Neurosci. 24, 76-84. doi: 10.1523/JNEUROSCI.4515-03.2004 
Zhao, W., Chuang, S. C., Bianchi, R., and Wong, R. K. (2011). Dual regulation of fragile $\mathrm{X}$ mental retardation protein by group I metabotropic glutamate receptors controls translation-dependent epileptogenesis in the hippocampus. J. Neurosci. 31, 725-734. doi: 10.1523/JNEUROSCI.2915-10.2011

Zhong, J., Chuang, S. C., Bianchi, R., Zhao, W., Lee, H., Fenton, A. A., et al. (2009). BC1 regulation of metabotropic glutamate receptor-mediated neuronal excitability. J. Neurosci. 29, 9977-9986. doi: 10.1523/JNEUROSCI.3893-08.2009

Ziyatdinova, S., Gurevicius, K., Kutchiashvili, N., Bolkvadze, T., Nissinen, J., Tanila, H., et al. (2011). Spontaneous epileptiform discharges in a mouse model of Alzheimer's disease are suppressed by antiepileptic drugs that block sodium channels. Epilepsy Res. 94, 75-85. doi: 10.1016/j.eplepsyres.2011.01.003
Conflict of Interest Statement: The authors declare that the research was conducted in the absence of any commercial or financial relationships that could be construed as a potential conflict of interest.

Copyright (c) 2016 Westmark, Chuang, Hays, Filon, Ray, Westmark, Gibson, Huber and Wong. This is an open-access article distributed under the terms of the Creative Commons Attribution License (CC BY). The use, distribution or reproduction in other forums is permitted, provided the original author(s) or licensor are credited and that the original publication in this journal is cited, in accordance with accepted academic practice. No use, distribution or reproduction is permitted which does not comply with these terms. 